\title{
ABSORÇÃO INTESTINAL DE D-XILOSE EM CRIANÇAS INFECTADAS PELO VÍRUS DA IMUNODEFICIÊNCIA HUMANA ${ }^{+}$
}

\author{
Nilza Medeiros PERIN ${ }^{1}$, Maria Marlene de Souza PIRES ${ }^{2}$ e Sílvia Modesto NASSAR ${ }^{3}$
}

RESUMO - Objetivos - Avaliar a absorção intestinal em crianças de 18 meses a 14 anos infectadas pelo HIV, atendidas em uma unidade de ambulatório e verificar se existe associação entre má absorção, diarréia, estado nutricional, alteração imunológica, parasitas entéricos clássicos e Cryptosporidium. Metodologia - A absorção intestinal foi investigada utilizandose a medida da D-xilose sérica. Amostras fecais foram colhidas para a pesquisa de pátogenos entéricos clássicos e Cryptosporidium. O tamanho da amostra foi calculado considerando a prevalência de $30 \%$ com precisão de $5 \%$ de alteração na absorção da D-xilose em crianças infectadas pelo HIV. Os procedimentos estatísticos utilizados foram: medidas descritivas, análise de correspondência múltipla e regressão logística. Resultados - Das 104 crianças estudadas, somente 8 (7,7\%) apresentaram o teste da D-xilose alterado e 33 (31,73\%) foram positivas para Cryptosporidium. A análise de correspondência múltipla aplicada aos dados encontrados sugeriu a associação entre o teste da D-xilose alterado e a presença de Cryptosporidium. Não se encontrou associação entre o teste alterado e diarréia, estado nutricional, alteração imunológica e parasistas entéricos clássicos. Conclusões - A má absorção intestinal avaliada pelo teste da Dxilose foi infreqüente nas crianças HIV positivas estudadas. O comprometimento intestinal, quando presente, parece estar relacionado com a presença de Cryptosporidium, porém não com diarréia, estado nutricional, alteração imunológica e parasistas entéricos clássicos.

DESCRITORES - Soropositividade para HIV. Infecções oportunistas relacionadas com a AIDS. Absorção intestinal. Xilose, metabolismo. Criptosporidiose. Criança.

\section{INTRODUÇÃO}

A síndrome da imunodeficiência adquirida (AIDS), doença causada pelo vírus da imunodeficiência humana (HIV), é caracterizada por profundo desarranjo da imunidade celular mediada $^{(5)}$. O HIV replica-se nos linfócitos e macrófagos de pessoas infectadas, levando à disfunção da imunidade celular com conseqüente imunodeficiência. A infecção pelo HIV é doença que acomete diversos sistemas, e o comprometimento de vários órgãos pode contribuir para a sua progressão ${ }^{(22)}$.

O trato gastrointestinal desempenha papel crítico na patogênese e morbidade associadas à AIDS. Como o maior órgão linfóide do corpo, o trato gastrointestinal é um reservatório potencial para o HIV e importante sítio para a imunodeficiência induzida pelo mesmo ${ }^{(65)}$. Após a infecção pelo HIV, uma série complexa de eventos imunológicos é

Trabalho realizado no ambulatório de atendimento de AIDS pediátrica do Hospital Infantil Joana de Gusmão, Florianópolis, SC, Brasil.

Mestre em Ciências Médicas, Universidade Federal de Santa Catarina. Médica do Serviço de Gastroenterologia Pediátrica do Hospital Infantil Joana de Gusmão.

Doutora em Medicina, Faculdade de Medicina da Universidade de São Paulo. Professora do Departamento de Pediatria e Chefe do Serviço de Metabologia do Hospital Infantil Joana de Gusmão.

Doutora em Engenharia Biomédica. Professora Titular do Departamento de Informática da Universidade Federal de Santa Catarina.

Endereço para correspondência: Dra. Nilza Medeiros Perin - Rua Luiz Delfino 89/502 - Bremen - Florianópolis, SC, Brasil. e-mail: nperin@fitnet.com.br 
iniciada dentro da mucosa do trato gastrointestinal, prejudicando os mecanismos de defesa entéricos não específicos. As manifestações gastrointestinais podem resultar da infecção pelo próprio $\mathrm{HIV}^{(44)}$, de infecções oportunistas ${ }^{(68)}$ ou neoplasias ${ }^{(18)}$. Sintomas gastrointestinais, como diarréia, perda de peso, dor abdominal e disfagia, têm sido encontrados em pacientes infectados pelo $\mathrm{HIV}^{(51)}$. Muitas vezes estes sintomas são associados a parasitas entéricos, como Cryptosporidium, Mycobacterium avium-intracellulare, citomegalovírus e outros ${ }^{(68)}$. A manifestação mais comum é a doença diarréica, que afeta 50\% a $90 \%$ dos pacientes com AIDS $^{(14)}$. Em estudo realizado no Estado do Ceará, Brasil, encontrou-se prevalência de diarréia em $51 \%$ dos pacientes avaliados $^{(49)}$. DWORKIN et al. ${ }^{(18)}$ detectaram a presença de diarréia em $55 \%$ dos casos analisados. Em outro estudo longitudinal, realizado na Itália com crianças infectadas pelo HIV, detectou-se diarréia em 58 das 132 crianças estudadas ${ }^{(39)}$. A diarréia pode ser grave, associada à desidratação e resistente a vários regimes terapêuticos ${ }^{(64)}$. A causa mais comum de diarréia em pacientes infectados pelo HIV são infecções oportunistas por parasitas entéricos ${ }^{(68)}$. Porém, em grande número de casos não se identifica uma etiologia específica ${ }^{(47)}$. A diarréia geralmente está associada à perda de peso, embora ambas possam ocorrer independentemente uma da outra ${ }^{(44)}$. Podem preceder o desenvolvimento das complicações relacionadas à AIDS ou ocorrer concomitantemente com outras manifestações clínicas da doença ${ }^{(29)}$.

Embora os parasitas entéricos sejam freqüentemente identificados como causadores de diarréia e perda de peso nos adultos infectados pelo HIV ${ }^{(68)}$, a incidência de infecção entérica nas crianças parece ser mais baixa ${ }^{(69)}$, e as relações entre parasitas entéricos e retardo do crescimento não são compreendidas claramente. A infecção entérica pode resultar em lesão intestinal e má absorção que, se não for compensada por apoio nutricional, pode gerar deficiência nutricional ${ }^{(65)}$. O desenvolvimento de desnutrição causa deficiência imune que, por sua vez, resulta em maior susceptibilidade à infecção entérica e o círculo é completado.

A prevalência, gravidade, causas e contribuição da diarréia e perda de peso para má absorção intestinal nos pacientes infectados pelo HIV são controversas. Não está clara, até o momento, a prevalência da má absorção intestinal em crianças HIV positivas e se ela está associada a quadros diarréicos. A má absorção intestinal tem sido relatada em crianças HIV positivas com e sem diarréia ${ }^{(32,69)}$. Alguns estudos sugerem que a má absorção é infreqüente e sem importância clínica, enquanto que outros reforçam a sua relevância nos pacientes com $\operatorname{AIDS}^{(45,52)}$. KOTLER et al. ${ }^{(45)}$, estudando pacientes com AIDS, encontraram comprometimento intestinal grave com má absorção de nutrientes. GUARINO et al. ${ }^{(32)}$ demonstraram, em crianças HIV positivas sintomáticas, envolvimento generalizado da função intestinal, incluindo má absorção dos principais nutrientes e lesão da integridade mucosa, sugerida por aumento da permeabilidade intestinal. Outro estudo ${ }^{(40)}$ com 47 crianças HIV positivas sintomáticas também demonstrou disfunção intestinal, levando à má absorção de gordura, carboidrato e proteína. Neste grupo, porém, a má absorção intestinal não foi associada à diarréia, nem à desnutrição. Em estudo longitudinal realizado em cinco crianças HIV positivas assintomáticas, foram encontradas, além da má absorção de carboidrato, perda de proteína e gordura nas fezes ${ }^{(32)}$. MILLER et al. ${ }^{(52)}$ demonstraram que a má absorção de carboidrato foi relativamente freqüente em crianças HIV positivas assintomáticas, ocorrendo em $40 \%$ dos casos. Por outro lado, KEATING et al. ${ }^{(42)}$ não evidenciaram má absorção intestinal em pacientes HIV positivos assintomáticos.

Existem muitas causas em potencial para a má absorção em pacientes infectados pelo HIV, incluindo alterações na função e estrutura gastrointestinal, e infecções oportunistas ${ }^{(35)}$. A má absorção nestes pacientes pode levar à desnutrição que, por sua vez, contribui para a morbidade e mortalidade. Além de afetar o crescimento, pode resultar em anormalidades imunológicas que exacerbariam o comprometimento da imunidade celular inerentes à infecção pelo $\mathrm{HIV}^{(22)}$. A disfunção intestinal também pode interferir adversamente com a habilidade de absorver medicações orais, tais como zidovudine $^{(58)}$

Investigações não-invasivas da função intestinal são úteis para monitorar e manusear as necessidades nutricionais das crianças HIV positivas. O teste da D-xilose é atualmente a mais confiável medida quantitativa da função absortiva intestinal, podendo ser utilizado para a avaliação da má absorção do intestino delgado em diversas circunstâncias clínicas ${ }^{(4,7,13,17,19,23)}$. Trata-se de teste simples e barato que vem sendo utilizado por mais de $40 \operatorname{anos}^{(24)}$. Em 1937, HELMER e FOUTS ${ }^{(36)}$ sugeriram que a absorção da xilose refletia a absorção intestinal de carboidrato no intestino humano. Posteriormente, ROLSTON e MATHAN ${ }^{(63)}$ demonstraram que a absorção da xilose é processo passivo, refletindo a área absortiva total do jejuno ao invés da absorção de carboidrato em si. A D-xilose é uma pentose encontrada em plantas e sua absorção correlaciona-se com a integridade gastrointestinal ${ }^{(41)}$. A absorção diminuída de D-xilose sugere diminuição da área absortiva do intestino ${ }^{(63)}$. Diversos trabalhos têm utilizado o teste da D-xilose para demonstrar má absorção em pacientes com $\operatorname{AIDS}^{(20,2644,67)}$. Estudos em pacientes HIV positivos com diarréia demonstraram uma absorção diminuída de D-xilose ${ }^{(21,66)}$. Em estudo realizado com crianças HIV positivas, constatou-se que aquelas que apresentavam absorção diminuída de D-xilose tinham maior chance de serem infectadas por parasitas entéricos ${ }^{(52)}$. Pacientes com AIDS que apresentaram o teste da D-xilose anormal tiveram grau mais intenso de desnutrição do que aqueles com teste normal ${ }^{(56)}$.

Não está claro na história natural do HIV quando a má absorção se torna evidente e como se relaciona com os sintomas, como perda de peso e diarréia. Estudos prospectivos da história natural da infecção pelo HIV em crianças, particularmente a relação entre má absorção, 
desnutrição e progressão da doença, podem propiciar o desenvolvimento de terapias nutricionais mais adequadas para estes pacientes.

Espera-se, com este estudo, avaliar a absorção intestinal em crianças infectadas verticalmente pelo HIV, sintomáticas, utilizando o teste da D-xilose e verificar se a má absorção, quando presente, está relacionada com diarréia, estado nutricional, alteração imunológica, parasitas entéricos clássicos e Cryptosporidium.

\section{MATERIAL E MÉTODOS}

Foi feito estudo transversal e descritivo para avaliar a absorção intestinal de crianças infectadas pelo HIV. A população estudada foi de crianças de 18 meses a 14 anos, infectadas pelo HIV por transmissão vertical, sintomáticas, em acompanhamento no Ambulatório de Atendimento de AIDS Pediátrica (GAAP), no Serviço de Infectologia do Hospital Infantil Joana de Gusmão (HIJG), em Florianópolis, SC, um Centro de Referência Estadual em AIDS Pediátrica, de $1^{\circ}$ de junho a 30 de outubro de 1999. Havia 320 crianças cadastradas no ambulatório, sendo a população alvo constituída de 160 crianças sintomáticas, que compareciam regularmente às consultas ambulatoriais. $\mathrm{O}$ diagnóstico e a classificação da infecção pelo HIV foram definidos de acordo com o estabelecido pelo Centers of Disease Control and Prevention (CDC, Atlanta, GA, EUA), de 1994(10).

Para estimar tamanho amostral mínimo, considerando uma prevalência de alteração na absorção da D-xilose em crianças HIV positivas de $30 \%$ e para precisão de $5 \%$, a amostra seria de 325 crianças. Corrigindo este valor para o tamanho da população alvo, a amostra estimada foi de pelo menos 100 crianças. Dessa forma, no período de coleta de dados previsto, a amostra estudada foi de 104 crianças.

Os pacientes foram considerados inelegíveis para o estudo quando apresentaram: recusa por parte da mãe, pai ou responsável, a participar do estudo ou à coleta de sangue, jejum incorreto previamente à coleta de sangue e ou problemas na coleta ou na realização dos exames laboratoriais.

O estudo foi projetado conforme as Diretrizes e Normas Regulamentadoras de Pesquisa Envolvendo Seres Humanos. Todos os pacientes receberam consentimento informado, aplicado por profissional médico não participante da pesquisa, que foi assinado pelo pai, mãe ou responsável.

Para a avaliação do estado nutricional escolheu-se a antropometria onde se considerou o peso para idade e a estatura para idade ${ }^{(3)}$. As medidas antropométricas obtidas eram pontuadas em gráficos do National Center for Health Statistics - NCHS ${ }^{(34)}$, bem como analisadas por programa de computação: Epi Info $6.04^{\circledR} /$ Epinutre (Organização Mundial da Saúde, Genebra, Suíça), que faz análise através do escore Z. Agruparam-se os pacientes em relação ao escore $Z$ peso para a idade em dois grupos: ausência de desnutrição energético-protéica
(DEP) (escore $\mathrm{Z}$ maior que - 2) e presença de DEP (escore $\mathrm{Z}$ menor ou igual a - 2). Da mesma forma, procedeu-se em relação ao escore $Z$ estatura para idade: estatura adequada para a idade (escore $Z$ maior que - 2) e estatura comprometida para a idade (escore $Z$ menor ou igual a - 2) ${ }^{(31,43)}$.

Foi considerada diarréia quando o paciente apresentou três ou mais evacuações de consistência amolecida ou líquida por período mínimo de 24 horas nos 30 dias que antecederam à coleta dos dados ${ }^{(55)}$.

\section{Investigação laboratorial}

Avaliação da absorção intestinal - Foi avaliada utilizando-se o teste da D-xilose. Após jejum de 8 horas foram administradas aos pacientes 0,5 gramas por quilograma de $\mathrm{D}$-xilose dissolvida em solução aquosa a $10 \%$ até no máximo $25 \mathrm{~g}$. Sessenta minutos após a administração da D-xilose, foi coletada amostra de sangue venoso. A D-xilose sangüínea foi estimada pelo método colorimétrico descrito por ROE e RICE ${ }^{(61)}$. Foram colhidas amostras em duplicata e o resultado final foi obtido através da média do resultado das duas amostras. Valor menor que $25 \mathrm{mg} / \mathrm{dL}$ foi considerado alterado ${ }^{(33,59)}$

Parasitológico de fezes - Foi realizado em amostra de fezes trazida pelo paciente no dia da coleta dos exames, que era colhida até 24 horas antes e armazenada sob refrigeração. Cada amostra foi dividida em duas, sendo examinadas separadamente para pesquisa de ovos e parasitas pelos métodos de sedimentação espontânea de HOFFMAN et al. ${ }^{(38)}$, LUTZ $^{(50)}$ e de MORAES ${ }^{(53)}$. O exame foi considerado positivo quando se identificou algum patógeno em pelo menos uma das amostras.

Pesquisa de Cryptosporidium - Parte da amostra de fezes trazida pelo paciente foi separada e dividida em duas. Após, foram concentradas através de centrífugo-sedimentação pelo formaldeído-éter ${ }^{(1,60)}$ e coradas pelo Ziehl Nielsen para pesquisa de Cryptosporidium ${ }^{25,37)}$. O exame foi considerado positivo quando se identificou o patógeno em pelo menos uma das amostras.

Linfócitos T CD4+ - A contagem de linfócitos T CD4+ foi realizada através de citometria de fluxo e expressa em número de células $^{(11)}$. A categoria imunológica foi definida em: ausência de alteração imunológica (percentagem de linfócitos T CD4+ maior ou igual que $25 \%$ ), moderada (porcentagem de linfócitos T CD4+ entre 15\%$24,9 \%$ ) ou grave (percentagem de linfócitos T CD4+ menor que $15 \%)^{(10)}$.

\section{Análise estatística}

Para avaliar a associação entre variáveis categóricas, utilizou-se a análise de correspondência múltipla $(\mathrm{ACM})^{(8,28)}$. Também de forma exploratória, utilizou-se a análise de regressão logística para avaliar a relação das variáveis independentes com a absorção de D-xilose. As 
observações foram estruturadas em uma base de dados, aplicando-se o programa Excel $7.0^{\circledR}\left(\right.$ Micrososft $\left.^{\circledR}\right)$ e, para análise estatística, empregou-se o programa Statistica $5.0^{\circledR}\left(\mathrm{StatSoft}^{\circledR}\right)$.

\section{RESULTADOS}

Foram analisadas 104 crianças. Destas, $59(56,73 \%)$ eram do sexo masculino e $45(43,26 \%)$ do feminino. A média de idade para o sexo masculino foi de 5,7 anos e desvio padrão de 2,9 anos e para o feminino foi de 5.9 anos e desvio padrão de 2,3 anos. A média de idade para ambos os grupos foi de 5,9 anos e desvio padrão de 2,6. A maior parte das crianças estudadas encontrava-se na faixa etária de 2 a 7 anos $(69,23 \%)$

Dos pacientes estudados, $96(92,3 \%)$ apresentaram o teste da Dxilose normal e $8(7,7 \%)$ alterado. Assim, ao nível de confiança de $95 \%$, estima-se que o percentual de exames alterados está entre $2,5 \%$ e $12,9 \%$. Dos pacientes que tiveram o teste normal, $56(58,33 \%)$ eram do sexo masculino e $40(41,67 \%)$ do feminino. Dos que apresentaram o teste alterado, $3(37,50 \%)$ eram do sexo masculino e $5(62,50 \%)$ do feminino. A média da D-xilose nas crianças estudadas foi de $42,8 \mathrm{mg} /$ dL e desvio padrão de $14,4 \mathrm{mg} / \mathrm{dL}$. O valor mais baixo de D-xilose foi de $16 \mathrm{mg} / \mathrm{dL}$ e o mais alto de $73 \mathrm{mg} / \mathrm{dL}$. Não houve associação dos valores da D-xilose com a idade (Figura 1 ).

\section{Características gerais da amostra estudada}

Dos 104 pacientes estudados, 19 (18,27\%) apresentaram diarréia

A média do escore $Z$ peso para idade para o sexo masculino foi de $-0,80$ e desvio padrão de 1,07 , e para o feminino foi de $-0,73$ e desvio padrão de 1,13 . A média para ambos os grupos foi de $-0,77$ e desvio padrão de 1,1 .

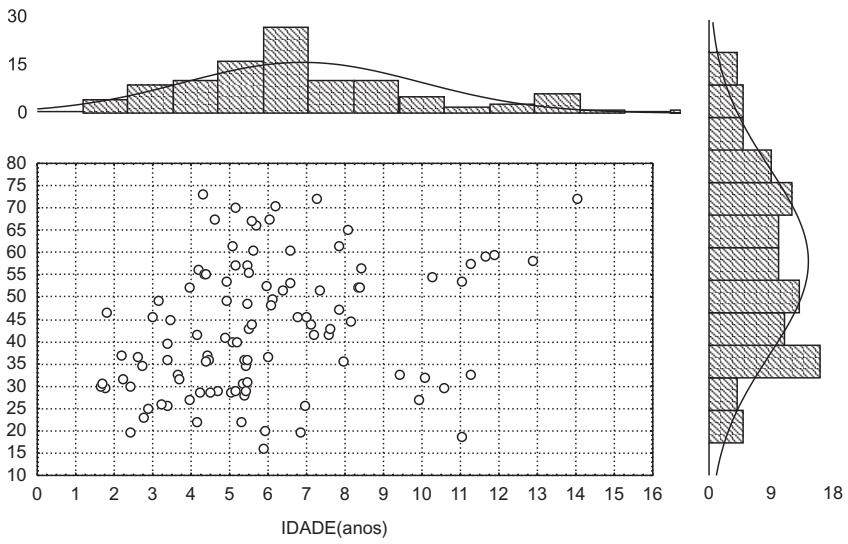

FIGURA 1 - Distribuição dos valores de D-xilose de acordo com a idade
Das 104 crianças estudadas, 93 (89,42\%) apresentaram escore Z peso para idade maior que - 2 e $11(10,58 \%)$ escore $Z$ peso para idade menor ou igual a - 2 (Tabela 1$)$.

TABELA 1 - Distribuição das crianças infectadas pelo HIV segundo o escore $\mathrm{Z}$ peso para idade em relação à faixa etária

\begin{tabular}{|c|c|c|c|c|c|c|}
\hline \multirow{3}{*}{$\begin{array}{c}\text { Faixa etária } \\
\text { (anos) }\end{array}$} & \multicolumn{4}{|c|}{ Escore $Z$ peso $x$ idade } & \multicolumn{2}{|c|}{ Total } \\
\hline & \multicolumn{2}{|c|}{$>-2$} & \multicolumn{2}{|c|}{$\leq-2$} & & \\
\hline & $\mathbf{n}$ & $\%$ & $\mathbf{n}$ & $\%$ & $\mathbf{n}$ & $\%$ \\
\hline menor que 2 & 4 & 100,00 & 0 & 0,00 & 4 & 3,85 \\
\hline $2 \longmapsto 7$ & 65 & 90,28 & 7 & 9,72 & 72 & 69,23 \\
\hline $7 \longmapsto 10$ & 16 & 94,11 & 1 & 5,88 & 17 & 16,35 \\
\hline$\geq 10$ & 8 & 72,72 & 3 & 27,27 & 11 & 10,58 \\
\hline Total & 93 & 89,42 & 11 & 10,58 & 104 & 100,00 \\
\hline
\end{tabular}

* Percentual em relação à coluna

A média do escore $Z$ estatura para a idade para o sexo masculino foi de $-0,99$ e desvio padrão de 1,14 e para o feminino foi de $-1,15$ e desvio padrão de 1,29. A média para ambos os grupos foi de $-1,06 \mathrm{e}$ desvio padrão de 1,2 .

Em relação ao escore $Z$ estatura para a idade, 78 (75\%) apresentaram escore $\mathrm{Z}$ maior que -2 e 26 (25\%) escore $\mathrm{Z}$ menor ou igual a -2 (Tabela 2)

TABELA 2 - Distribuição das crianças infectadas pelo HIV segundo o escore $\mathrm{Z}$ estatura para idade em relação à faixa etária

\begin{tabular}{|c|c|c|c|c|c|c|}
\hline \multirow{3}{*}{$\begin{array}{c}\text { Faixa etária } \\
\text { (anos) }\end{array}$} & \multicolumn{4}{|c|}{ Escore $Z$ peso $x$ idade } & \multicolumn{2}{|c|}{ Total } \\
\hline & \multicolumn{2}{|c|}{$>-2$} & \multicolumn{2}{|c|}{$\leq-2$} & & \\
\hline & $\mathbf{n}$ & $\%$ & $\mathbf{n}$ & $\%$ & $\mathbf{n}$ & $\%$ \\
\hline menor que 2 & 3 & 75,00 & 1 & 25,00 & 4 & 3,85 \\
\hline $2 \longmapsto 7$ & 58 & 80,55 & 14 & 19,44 & 72 & 69,23 \\
\hline $7 \longmapsto 10$ & 11 & 64,70 & 6 & 35,29 & 17 & 16,35 \\
\hline$\geq 10$ & 6 & 54,50 & 5 & 45,45 & 11 & 10,58 \\
\hline Total & 78 & 75,00 & 26 & 25,00 & 104 & 100,00 \\
\hline
\end{tabular}

* Percentual em relação à coluna

Quanto à categoria imunológica, 53 (50,96\%) pacientes apresentaram ausência de alteração imunológica, 35 (33,65\%) alteração imunológica moderada e $16(15,38 \%)$ grave.

Quanto à presença de Cryptosporidium, 33 (31,73\%) pacientes foram positivos e $71(68,27 \%)$ negativos.

Em $11(10,57 \%)$ pacientes o exame parasitológico de fezes foi positivo. Quatro crianças foram positivas para Endolimax nana, oito para Giardia lamblia, um para Ascaris lumbricoides e um para Entamoeba histolytica. 


\section{Descrição das variáveis analisadas em relação à D-xilose}

Das oito crianças que tiveram o teste da D-xilose alterado, somente uma $(18,75 \%)$ apresentou diarréia. Todas elas apresentaram escore $\mathrm{Z}$ peso a para idade maior que -2 e $6(75 \%)$ escore $Z$ estatura para a idade maior que -2. Quatro (50\%) não apresentaram alteração imunológica, 2 (25\%) apresentaram alteração imunológica moderada e 2 (25\%) apresentaram alteração imunológica grave. Quatro (50\%) foram positivas para Cryptosporidium e 4 (25\%) negativas. Em nenhuma criança que apresentou o teste alterado foi identificado algum parasita. A Tabela 3 ilustra a descrição de todas as variáveis em relação à D-xilose.

TABELA 3 - Descrição das variáveis analisadas em relação à D-xilose

\begin{tabular}{lcccc}
\hline \multirow{2}{*}{ Variáveis } & \multicolumn{4}{c}{ D-xilose } \\
\cline { 2 - 5 } & Normal & \multicolumn{2}{c}{ Alterada } \\
& $\mathbf{n}$ & $\mathbf{\%}$ & $\mathbf{n}$ & $\mathbf{\%}$ \\
\hline Diarréia & & & & \\
$\quad$ Ausente & 78 & 81,25 & 7 & 87,50 \\
$\quad$ Presente & 18 & 18,75 & 1 & 18,75 \\
Escore Z(P/I)* & & & & \\
$>-2$ & 85 & 88,55 & 8 & 100,00 \\
$<-2$ & 11 & 11,46 & 0 & 0,00 \\
Escore Z (E/I)** & & & & \\
$>-2$ & 72 & 75,00 & 6 & 75,00 \\
$\quad<-2$ & 24 & 25,00 & 2 & 25,00 \\
Alteração Imunológica & & & & \\
$\quad$ Ausente & 49 & 51,04 & 4 & 50,00 \\
$\quad$ Moderada & 33 & 34,38 & 2 & 25,00 \\
$\quad$ Grave & 14 & 14,58 & 2 & 25,00 \\
Cryptosporidium & & & & \\
$\quad$ Negativo & 67 & 69,79 & 4 & 50,00 \\
$\quad$ Positivo & 29 & 30,21 & 4 & 50,00 \\
Parasitológico Fezes & & & & \\
$\quad$ Negativo & 85 & 88,54 & 8 & 100,00 \\
$\quad$ Positivo & 11 & 11,46 & 0 & 0,00 \\
\hline
\end{tabular}

* $(\mathrm{P} / \mathrm{I})=$ peso para idade

** $(\mathrm{E} / \mathrm{I})=$ estatura para idade

\section{Padrão de comportamento da D-xilose em relação às variáveis}

Neste item busca-se explorar a associação do teste da D-xilose alterado com presença de diarréia, de alteração imunológica, de Cryptosporidium, estado nutricional e positividade do parasitológico de fezes. Foram analisadas 1 variável dependente e 6 variáveis independentes, que resultaram em 12 categorias, às quais foi aplicada a ACM, buscando identificar associação entre variáveis segundo suas características. Para fins de análise, as categorias imunológicas foram divididas em dois grupos: ausência (percentagem de linfócitos T CD4+ maior ou igual que $25 \%$ ) e presença de alteração imunológica (percentagem de linfócitos T CD4+ menor que 25\%).

A Figura 2 ilustra a associação das variáveis analisadas pela ACM. Sugere tendência de associação entre o teste da D-xilose normal e ausência de Cryptosporidium. Há também evidências que sugerem associação entre o teste da D-xilose alterado e a presença de Cryptosporidium. A presença ou ausência de diarréia e de alteração imunológica e a positividade ou negatividade do exame parasitológico de fezes não trouxeram informações sobre má absorção (teste da Dxilose normal ou alterado). Da mesma maneira, não houve evidência quanto à associação do teste da $\mathrm{D}$-xilose com o estado nutricional dos pacientes neste estudo.

Ainda explorando a associação entre todas as variáveis e o teste da D-xilose, utilizou-se a regressão logística para variáveis dicotômicas. Corroborando os achados da análise pela $\mathrm{ACM}$, o modelo não foi estatisticamente significativo.

\section{DISCUSSÃO}

A alteração na absorção intestinal tem sido descrita em pacientes infectados pelo HIV, mas os estudos geralmente foram feitos com pequeno número de pacientes ${ }^{(18,20,48,52,66,67)}$. Dos 104 pacientes

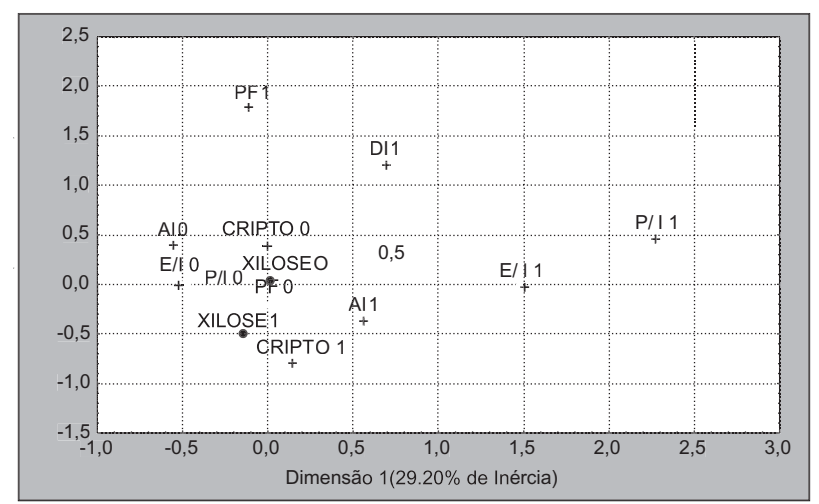

XILOSE 0 D-xilose normal

XILOSE 1 D-xilose alterada

DI 0 Ausência de diarréia

DI 1 Presença de diarréia

P/I 0 Escore $Z$ peso para idade: ausência de DEP

$\mathrm{P} / \mathrm{I} 1$ Escore $Z$ peso para idade: presença de DEP

E/I 0 Escore $Z$ estatura para idade: estatura adequada para idade

E/I 1 Escore $Z$ estatura para idade: estatura comprometida para idade

AI 0 Ausência de alteração imunológica

AI 1 Presença de alteração imunológica

PF $0 \quad$ Parasitológico de fezes negativo

PF 1 Parasitológico de fezes positivo

CRIPTO 0 Cryptosporidium negativo

CRIPTO 1 Cryptosporidium positivo

FIGURA 2 - Associação entre as categorias das variáveis para as crianças infectadas pelo HIV 
estudados, $92,3 \%$ apresentaram o teste da D-xilose normal e 7,7\% alterado. O baixo número de resultados anormais sugere que a absorção intestinal de D-xilose está preservada na maioria dos pacientes estudados. Esta baixa incidência de resultados anormais pode ser devido ao fato de que os pacientes estudados, apesar de apresentarem classificações da infecção diversas, encontravam-se controlados do ponto de vista médico. Os mesmos estavam sob uso de medicamentos anti-retrovirais eficazes, recebiam acompanhamento médico periódico, bem como suporte nutricional. Recentemente, talvez até pelas mudanças medicamentosas que, de certa forma diminuíram em muito a chance do paciente infectado pelo HIV caminhar para uma grande caquexia, os achados de problemas relacionados com o trato gastrointestinal vêm diminuindo de maneira significativa ${ }^{(6)}$. CANANI et al. ${ }^{(6)}$ estudaram a função intestinal em um grupo de crianças infectadas pelo HIV antes e depois do início de terapêutica anti-retroviral combinada. Constataram restauração da função intestinal após o tratamento em todas as crianças estudadas.

A maioria das crianças infectadas pelo HIV apresenta diarréia em algum momento da evolução de sua doença ${ }^{(39)}$. Neste estudo verificouse que, dos 104 pacientes estudados, 19 (18,27\%) apresentaram diarréia. Na maioria dos casos de diarréia não se identificou nenhum patógeno entérico. Isto não é incomum em crianças infectadas pelo $\mathrm{HIV}^{(69)}$, o que pode ser devido ao fato da maioria dos parasitas entéricos em pacientes infectados pelo HIV serem intracelulares, requerendo biopsia intestinal para identificação do agente etiológico ${ }^{(52)}$. Neste estudo não se pesquisou parasitas específicos relacionados à AIDS, como Microsporidia e Mycobacterium avium-intracellulare, por requererem exames mais invasivos, como biopsia intestinal ${ }^{(45,30)}$. Por outro lado, tem sido descrito por diversos autores uma enteropatia associada à infecção pelo HIV em alguns casos em que não é possível identificar-se nenhum patógeno entérico em pacientes com diarréia ${ }^{(26,}$

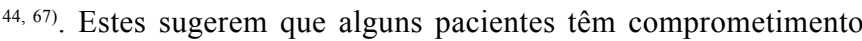
intestinal causado pelo próprio HIV. Dados sobre a histologia intestinal são necessários para determinar se a má absorção intestinal está associada à enteropatia induzida pelo $\operatorname{HIV}^{(26,44)}$.

Não existem trabalhos que demonstrem alguma relação significativa entre parasitas intestinais comuns e $\operatorname{HIV}^{(12)}$. Neste estudo, somente 11 pacientes apresentaram parasitológico de fezes positivo, sendo que destes, 8 eram devido à Giardia lamblia.

Entretanto, o Cryptosporidium foi detectado em 33 (31,73\%) dos casos. Os achados desta série foram semelhantes aos de PAVIA et al. ${ }^{(57)}$, que investigaram a presença de parasitas intestinais em crianças HIV positivas e nenhum outro patógeno, além do Cryptosporidium, foi associado ao HIV. A criptosporidiose intestinal representa problema clínico relevante em pacientes com AIDS, com prevalência de $4 \%-50 \%{ }^{(2)}$. Em estudo realizado em crianças com diarréia na África, isolou-se o Cryptosporidium nas fezes de $14 \%$ das crianças HIV positivas e $6 \%$ nas negativas ${ }^{(12)}$. Em 1985, o CDC relatou que 5\% das crianças americanas infectadas pelo HIV apresentavam criptosporidiose $^{(62)}$. O Cryptosporidium foi detectado em 14 de 174 crianças com AIDS relatadas para o $\mathrm{CDC}^{(54)}$ e em 2 de 11 crianças com diarréia $^{(52)}$. Foi associado com diarréia crônica em um pequeno número de crianças HIV positivas na Tanzânia, mas sua prevalência não foi diferente da encontrada em crianças HIV negativas ${ }^{(9)}$. Em alguns pacientes com AIDS, a excreção de oocistos está ligada à diarréia grave e prolongada ${ }^{(15)}$. Entretanto, nem todos os pacientes com Cryptosporidium são sintomáticos. Pacientes assintomáticos ${ }^{(70)}$ ou com sintomas leves ${ }^{(15)}$ têm sido identificados. Neste estudo, a maioria dos pacientes com infecção pelo Cryptosporidium era assintomática.

A infecção pelo Cryptosporidium em pacientes com AIDS tem sido ligada à má absorção de D-xilose ${ }^{(16,27,45,46)}$. GOODGAME et al. ${ }^{(27)}$ demonstraram associação entre a presença de Cryptosporidium em pacientes com AIDS com comprometimento intestinal manifestado por atrofia vilositária, má absorção de D-xilose e alteração na permeabilidade intestinal. Neste trabalho também se encontraram evidências que sugerem associação entre o teste da D-xilose alterado e a presença de Cryptosporidium. A impressão que se tem é de que pacientes com AIDS podem ter má absorção, particularmente aqueles com Cryptosporidium ${ }^{(26,45,67)}$. A associação entre alguns parasitas mais comumente identificáveis e má absorção foi relatada em pacientes HIV positivos com diarréia por MILLER et al. ${ }^{(52)}$, porém não por YOLKEN et al. ${ }^{(69)}$

A má absorção intestinal não foi associada à diarréia, confirmando dados reportados anteriormente ${ }^{(40)}$. Não se verificou nenhuma associação entre a absorção intestinal investigada pelo teste da Dxilose e presença ou ausência de diarréia. EHRENPREIS et al. ${ }^{(20)}$ demonstraram que a má absorção de D-xilose não ocorreu em todos os pacientes com diarréia crônica. Entretanto, níveis de D-xilose menores que $13 \mathrm{mg} / \mathrm{dL}$ tinham valor preditivo positivo para caquexia de $83 \% \mathrm{e}$ para óbito, dentro de 1 ano, de $92 \%$. Nestes pacientes a má absorção foi identificada somente após o desenvolvimento de diarréia crônica e perda de peso, não podendo ser concluído se a perda de peso foi causa ou conseqüência da má absorção.

Crianças com má absorção intestinal não eram mais desnutridas do que aquelas com absorção normal. Esta surpreendente falta de associação foi também observada por MILLER et al. ${ }^{(52)}$, e tem duas explicações possíveis. Primeiro, que a má absorção intestinal é condição transitória em crianças sintomáticas infectadas pelo HIV, devendo contribuir para a desnutrição somente quando se prolonga por mais tempo. Segundo, a fisiopatologia da desnutrição é multifatorial nas crianças infectadas pelo HIV e diferentes fatores como, condição sócioeconômica, erro alimentar, doenças associadas e dinâmica familiar podem contribuir para sua ocorrência. Semelhante aos achados de MILLER et al. ${ }^{(52)}$, constatou-se em alguns casos, comprometimento do estado nutricional em crianças com o teste da D-xilose normal, sugerindo que existem outros fatores que podem concorrer para um 
comprometimento do estado nutricional em doentes HIV positivos. Alguns pacientes com comprometimento do estado nutricional tinham absorção intestinal preservada e vice-versa, outros diarréia e absorção intestinal preservada, enquanto que alguns sem diarréia tinham má absorção. Estes dados reforçam os mecanismos patogênicos multifatoriais responsáveis pelo estado clínico na AIDS.

Uma relação entre o grau de imunodeficiência e má absorção foi relatada em adultos com $\operatorname{AIDS}^{(42)}$. Entretanto, em um grupo de crianças infectadas pelo HIV não foi encontrada associação entre baixos níveis de LTCD4+ e má absorção ${ }^{(40)}$. Do mesmo modo, nas crianças estudadas a má absorção intestinal não foi associada com baixos níveis de LTCD4+.

Em conclusão, este estudo sugere que a má absorção intestinal foi infreqüente nas crianças estudadas, sendo que o comprometimento intestinal, quando presente, pode ser silencioso, não estando relacionado com sintomas clínicos como diarréia e com o estado nutricional. $\mathrm{O}$ comprometimento intestinal parece estar relacionado à presença de Cryptosporidium.

Perin NM, Pires MMS, Nassar SM. Intestinal absorption of D-xilose in children infected with the human immunodeficiency virus. Arq Gastroenterol 2001;38(4):261-268.

ABSTRACT - Aim - To evaluate the intestinal absorption in HIV-infected children children 14 months to 14 years and to investigate its relationship to diarrhea, nutritional status, immune dysfunction, classical enteric parasites and Cryptosporidium. Methods - Intestinal absorption was investigated by measuring serum D-xylose. Fecal samples were investigated for classical pathogens and Cryptosporidium. The sample size was calculated considering a 30\% prevalence of altered D-xylose absorption in HIV-infected children with a $5 \%$ accuracy. Statistical procedures used were: descriptive measurements, multiple correspondence analysis and logistic regression. Results - D-xylose absorption was altered in only 8 out of 104 (7,7\%) and Cryptosporidium was positive in 33 out of 104 (31,73\%) HIV-infected children. The multiple correspondence analysis suggested an association between an altered $D$-xylose test and Cryptosporidium. D-xylose malabsorption was not associated with diarrhea, nutritional status, immune disfunction and classic enteric parasites. Conclusions - Intestinal malabsorption evaluated through the D-xylose test was an uncommon finding in HIV-infected children. Intestinal dysfunction when present seems to be related to Cryptosporidium, but not to diarrhea, nutritional status, immune disfunction and classic enteric parasites.

HEADINGS - HIV seropositivity. AIDS-related opportunistic infections. Intestinal absorptions. Xylose, metabolism. Cryptosporidiosis. Child.

\section{REFERÊNCIAS BIBLIOGRÁFICAS}

1. Allen AVH, Ridley DS. Further observations on the formol ether concentration techique parasites. J Clin Pathol 1970;23:545-6.

2. Angus KW. Cryptosporidiosis and AIDS. Baillieres Clin Gastroenterol 1990;4:425-41.

3. Azcue MP, Pencharz PB. Diagnóstico nutricional. In: Carrazza FR, Marcondes E, editors. Nutrição clínica em pediatria. São Paulo; Sarvier 1991. p.160-86.

4. Benson JA, Culver PJ, Ragland S, Jones CM, Drummey GD, Bougas E. The Dxylose absorption test in malabsorption syndromes. N Engl J Med 1957;256:3359 .

5. Bowen DL, Lane HC, Fauci AS. Immunopathogenesis of the acquired immunodeficincy syndrome. Ann Intern Med 1985;103:704-9.

6. Canani RB, Spagnuolo MI, Cirillo P, Guarino A. Ritonavir combination therapy restores intestinal function in children with advanced HIV disease. J Acquir Immune Defic Syndr 1999;21:307-12.

7. Carroccio A, Iacono G, Montalto G, Cavataio F, Soresi M, Kazmierska I, Notarbartolo A. Immunologic and absorptive tests in celiac disease: can they replace intestinal biopsies? Scand J Gastroenterol 1993;28:673-6.

8. Carrol JD, Green PE, Schaffer CM. Interpoint distance comparisons in correspondence analysis. J Marketing Res 1986;23:271-80.

9. Cegielski JP, Rav EJ, Martin SR, Msengi AE, Dukes CS, Mbise R, Redding Lallinger R, Minjas JN, Wilson ML, Shao J, Durack DT. Intestinal parasites and HIV infection in Tanzanian children with chronic diarrhea. AIDS 1993;7:213 21.

10. Centers for Disease Control and Prevention. 1994 revised classification system of human immunodeficiency virus infection in children less than 13 years of age. MMWR 1994;43:1-10
11. Centers for Disease Control and Prevention. 1997 revised guidelines for performing CD4+ T-cell determinations in persons infected with human immunodeficiency virus (HIV). MMWR 1997;46:1-29.

12. Chintu C, Luo C, Baboo S, Khumalo-Ngwenya B, Mathewson J, DuPont HL, Zumla A. Intestinal parasites in HIV-seropositive Zambian children with diarrhea. J Trop Pediatrics 1995;41:149-152.

13. Christie DL. Use of one-hour blood xylose test as an indicator of small bowel mucosal disease. J Pediatr 1978;92:725-8.

14. Chui DW, Owen RL. AIDS and the gut. J Gastroenterol Hepatol 1994;9:331-3

15. Connolly G, Forbes A, Gazzard B. Investigation of seemingly pathogen-negative diarrhea in patients infected with HIV-1. Gut 1990;31:886-9.

16. Connoly G, Dyden M, Shazson D, Gazzard B. Cryptosporidial diarrhea in AIDS and its treatment. Gut 1988;29:593-7.

17. Craig RM, Ehrenpreis E. D-xylose testing. J Clin Gastroenterol 1999;29:143 50 .

18. Dworkin B, Wormser GP, Rosenthal WS, Heier SK, Braunstein M, Weiss L, Jankoski R, Levy D, Weiselberg S. Gastrointestinal manifestations of the acquired immunodeficiency syndrome: a review of 22 cases. Am J Gastroenterol $1985 ; 80: 774-8$

19. Eberts TJ, Sample RH, Glick MR, Ellis GH. A simplified colorimetric micromethod for xylose in serum or urine with phoroglucinol. Clin Chem 1979;25:1440-3.

20. Ehrenpreis ED, Carlson SJ, Boorstein HL, Craig RM. Malabsorption and deficiency of vitamin B12 in HIV-infected patients with chronic diarrhea. Dig Dis Sci 1994;39:2159-62.

21. Ehrenpreis ED, Ganger DR, Kochvar GT, Patterson BK, Craig RM. D-xylose malabsorption: characteristic finding in patients with AIDS wasting syndrome and chronic diarrhea. J Acquir Immune Defic Syndr 1992;5:1047-50.

22. Falloon J, Eddy J, Winer L, Pizzo PA. Human immunodeficiency virus infection in children. J Pediatr 1989;114:1-30. 
23. Fordtran JS, Soergel KH, Ingelfinger FJ. Intestinal absorption of D-xylose in man. Gut 1989;30:1686-91.

24. Fourman LPR. The absorption of D-xylose in steatorhea. Clin Sci 1948;6:289-94.

25. Garcia LS, Brucker DA, Brewer TC, Shimizu RY. Techinques for the recovery and identification of Cryptosporidium oocysts from stool specimens. J Clin Microbiol 1983;18:185-90

26. Gillin JS, Shike M, Alcock N, Urmacher C, Kron S, Kurtz RC, Ligthdale CJ, Winwaver SJ. Malabsorption and mucosal abnormalities of the small intestine in the acquired immunodeficiency syndrome. Ann Intern Med 1985;102:619-22.

27. Goodgame RW, Kimball K, Ou C-H, White AC, Genta RM, Lifschitz CH, Chappel $\mathrm{CL}$. Intestinal function and injury in acquired immunodeficiency syndromerelated cryptosporidiosis. Gastroenterology 1995;108:1075-82.

28. Greenacre MJ, Hastie T. The geometric interpretation of correspondence analysis J Am Stat Assoc 1987;1987:437-47.

29. Greene JB, Sidhu GS, Lewin S, Levine JF, Masur H, Simberkoff MS, Nicholas P, Good RC, Zolla Pazner SB, Pollock AA, Tapper ML, Holzman RS. Mycobacterium avium-intracelulare: a cause of disseminated life-threatening infection in homossexuals and drug abusers. Ann Intern Med 1982;97:539-46.

30. Greenson JK, Belitsos PC, Yardley JH. AIDS enteropathy: occult enteric infections and duodenal mucosal alterations in chronic diarrhea. Ann Intern Med 1991;114:366-72.

31. Griffiths M. Growth monitoring. Washington: American Public Health Association. International Health Programs. Primary Health Care Issues 1; 1981. (Report $n^{\circ} 3$ ).

32. Guarino A, Castaldo A, Russo S, Spagnuolo M, Canani RB, Tarallo L, DiBenedetto L Rubino A. Enteric cryptosporidiosis in pediatric HIV infection. J Pediatr Gastroenterol Nutr 1997;25:182-7.

33. Guarino A, Tarallo L, Guandalini S, Troncone R, Albano F, Rubino A. Impaired intestinal function in symptomatic HIV infection. J Pediatr Gastroenterol Nutr $1991 ; 12: 453-8$.

34. Hamill PV. NCHS growth curves for children birth - 18 years. Washington: US Government Printing Office; 1977. (Vital and Health Stat. Series 11; 165).

35. Hecker LM, Kotler DP. Malnutrition in patients with AIDS. Nutr Rev 1990;48:393-401.

36. Helmer OM, Fouts PJ. Gastrointestinal studies: VII. Excretion of xylose in pernicious anemia. J Clin Invest 1937;16:343-9.

37. Henriksen SA, Pohlenz JFL. Stainig of cryptosporidia by a modified Ziehl Nielsen technique. Acta Vet Scand 1981;22:594-6.

38. Hoffman WA, Pons JA, Janer JL. The sedimentation-concentration method in schistosomiasis mansoni. Puerto Rico J Publ Hlth 1934;9:281-98.

39. Italian Multicentre Study Group. Epidemiology and clinical features of pediatric HIV infection: results from an Italian multicentric study in 544 children. Lancet 1988;2:1046-8.

40. Italian Paediatric Intestinal HIV Study Group. Intestinal malabsorption of HIVinfected children: relationship to diarrhoea, failure to thrive, enteric microorganisms and immune impairment. AIDS 1993;7(11):1435-40.

41. Johnstone TW. Pentosuria, chronic and alimentary. Edinburgh Med J 1906;20:138-48.

42. Keating J, Bjarnason I, Somasundaram S, Macpherson A, Francis N, Price AB, Sharpstone D, Smithson J, Menzies IS, Gazzard BG. Intestinal absorptive capacity, intestinal permeability and jejunal histology in HIV and their relation to diarrhoea. Gut 1995;37:623-9.

43. Keller W, Filmore CM. The prevalence of protein-energy malnutrition. World Health Sta Q 1983;36:129-67.

44. Kotler DP, Gaetz HP, Lange M, Klein EB, Holt PR. Enteropathy associated with the acquired immunodeficiency syndrome. Ann Intern Med 1984;101:421-8.

45. Kotler DP, Francisco A, Clayton F, Scholes JV. Small intestinal injury and parasitic diseases in AIDS. Ann Intern Med 1990;113:444-9.

46. Kotler D, Reka S, Chow K, Orenstein J. Effects of enteric parasitoses and HIV infection upon small intestinal structure and function in patients with AIDS. J Clin Gastroenterol 1993;16:10-5.

47. Laughon BE, Druckman DA, Vernon A, Quinn TC, Polk BF, Modlin JF, Yolken RH, Barttet JG. Prevalence of enteric pathogens in homosexual men with and without acquired immunodeficiency syndrome. Gastroenterology 1988;94:984-93.
48. Lim SG, Menzies IS, Lee AC, Johnson MA, Pounder RE. Intestinal permeability and function in patients infected with human immunodeficiency virus. Scand J Gastroenterol 1993;28:573-80.

49. Lima AAM, Silva TMJ, Gifoni AMR, Barret LJ, McAulife IT, Bao Y, Fox, JW, Fedorko DP, Guerrant RL. Mucosal injury and disruption of intestinal barrier function in HIV-infected individuals with and without diarhea and cryptosporidiosis in northeast Brazil. Am J Gastroenterol 1997;92:1861-5.

50. Lutz AO. Schistosomun mansoni e a schistosomose, segundo observações feitas no Brasil. Mem Inst Oswaldo Cruz 1919;11:121-55.

51. May GR, Gill MJ, Church DL, Sutherland LR. Gastrointestinal symptoms in ambulatory HIV-infected patients. Dig Dis Sci 1993;38:1388-94.

52. Miller TL, Orav EJ, Martin SR, Cooper ER, McIntosh K, Winter HS. Malnutrition and carbohydrate malabsorption in children with vertically transmitted human immunodeficiency virus 1 infection. Gastroenterology 1991;100:1269-302.

53. Moraes RG. Contribuição para o estudo do Strongyloides stercoralis e da estrongiloidíase no Brasil. Rev Serv Saúde Públ 1948;1:507-624.

54. Navin TR. Cryptosporidiosis in patients with AIDS. J Infect Dis 1987;155:150.

55. Organizacion Mundial de la Salud. Manejo y prevencion de la diarrea: pautas prácticas. 3d. 1994.

56. Ott M, Wegner A, Caspary WF, Lembcke B. Intestinal absorption and malnutrition in patients with the acquired immunodeficiency syndrome (AIDS). Z Gastroenterol $1993 ; 31: 661-5$

57. Pavia AT, Long EG, Ryder RW, Nsa W, Puhr ND, Wells JG, Martin P, Tauxe RV, Griffin PM. Diarrhea among African children born to human immunodeficiency virus-1-infected mothers: clinical, microbiologic and epidemiologic features. Pediatr Infect Dis 1992;11:996-1003.

58. Pizzo PA. Emerging concepts in the treatment of HIV infection in children. JAMA 1989;262:1989-92.

59. Rich EJ, Christie DL. Anti-gliadin antibody panel and xylose absorption test in screening for celiac disease. J Pediatr Gastroenterol Nutr 1990;10:174-8.

60. Ritchie LS. An ether sedimentation technique for routine stool examinations. Bull US Army Med Dept 1948;8:326.

61. Roe JH, Rice EW. A photomeric method for the determination of free pentoses in animal tissues. J Biol Chem 1948;173:507-12

62. Rogers M, Thomas P, Starcher E, Noa M, Bush T, Jaffe H. Acquired immunodeficiency syndrome in children: report from the Centers for Disease Control national surveillance, 1982 to 1985 . Pediatrics 1987;79:1008-14.

63. Rolston DDK, Mathan VI. Xylose transport in human jejunum. Dig Dis Sci 1989;34:553-8.

64. Shapiro WL, Kain ZN. Diarrhea in infants with AIDS. N Engl J Med 1988;319:517.

65. Smith PD, Mai UEH. Immunopathophysiology of gastrointestinal disease in HIV infection. Gastroenterol Clin North Am 1992;21:331-45.

66. Sutherland LR, Church DL, Gill MJ, Kelly JK, Hwang WS, Bryant HE. Gastrointestinal function and structure in HIV-positive patients. Can Med Assoc J 1990;143:641-6.

67. Ullrich R, Zeitz M, Heise W, Láge M, Hoffken G, Riecken EO. Small intestinal structure and function in patients infected with human immunodeficiency virus (HIV): evidence for HIV-induced enteropathy. Ann Intern Med 1989;111:1521.

68. Ullrich R, Heise W, Bergs C, Lage M, Riecken EO, Zeitz M. Gastrointestinal symptoms in patients infected with human immunodeficiency virus: relevance of infective agents isolated from gastrointestinal tract. Gut 1992;33:1080-4.

69. Yolken RH, Hart W, Oung I, Shiff C, Greenson J, Perman JA. Gastrointestinal disfunction and disaccharide intolerance in children infected with the human immunodeficiency virus. J Pediatr 1991;118:359-63.

70. Zar F, Geiseler P, Brown V. Asymptomatic carriage without symptoms in the acquired immunodeficiency syndrome [letter]. J Infect Dis 1985;151:195.

Recebido em 16/11/2000 Aprovado em 30/7/2001. 